\title{
Benefícios flexíveis: estudo de caso em uma indústria de autopeças
}

\author{
Francisleine da Silva Santos \\ Margareth Ines Mother Caregnatto \\ Verena Alice Borelli \\ Adrieli Alves Pereira Radaelli \\ Paula Patrícia Ganzer \\ Cassiane Chais \\ Eric Charles Henri Dorion \\ Pelayo Munhoz Olea
}

\author{
Graduada em Administração. Faculdade da Serra Gaúcha (FSG) - Brasil. fran.cx@hotmail.com \\ Mestra em Gestão e Estratégias em Negócios. Faculdade da Serra Gaúcha (FSG) - Brasil. margaimc@terra.com.br \\ Doutoranda em Administração. Universidade de Caxias do Sul (UCS) - Brasil. verena.borelli@gmail.com \\ Doutoranda em Administração. Universidade de Caxias do Sul (UCS) - Brasil. adrieli.radaelli@gmail.com \\ Doutoranda em Administração. Universidade de Caxias do Sul (UCS) - Brasil. ganzer.paula@gmail.com \\ Doutoranda em Administração pela Universidade de Caxias do Sul (UCS) - Brasil. cassichais@gmail.com \\ Doutor em Administração de Empresas. Universidade de Caxias do Sul (UCS) - Brasil. echdorion@gmail.com \\ Doutor em Administração. Universidade de Caxias do Sul (UCS) - Brasil. pelayo.olea@gmail.com
}

RESUMO

As empresas estão investindo em diversas estratégias para atrair e reter talentos. Uma delas é a implantação de um plano de benefícios flexíveis, que possibilita o funcionário escolher entre uma série de benefícios. $O$ objetivo geral deste artigo é investigar o que pensam os colaboradores quanto a implantação de um plano flexível de benefícios. O estudo é fundamentado com base no referencial teórico de alguns autores, como, Boog e Boog (2002), Maximiano (2012), Robbins (2005), Marras (2011) e outros. A metodologia utilizada é estudo de caso, com caráter exploratório-descritivo e abordagem qualiquantitativa. Analisando o resultado do questionário aplicado, considera-se viável a implantação de um programa de benefícios flexíveis na empresa, pois $72 \%$ dos respondentes entendem que os benefícios flexíveis são fator importante para retenção de talentos e motivação de pessoal e $69 \%$ não estão satisfeitos com os benefícios oferecidos pela empresa.

Palavras-chave: Benefícios Flexíveis. Retenção. Talentos. Motivação.

\section{Flexible benefits: a case study in an automotive industry}

\begin{abstract}
Companies are investing in many strategies to attract and retain talents. One of them is the implementation of a flexible benefits plan that allows the employee to choose among a number of benefits. The aim of this paper is to investigate the opinion of employees regarding the implementation of a flexible plan of benefits. The study is based on the theoretical framework of Boog and Boog (2002), Maximiano (2012), Robbins (2005), Marras (2011) and others. The methodology used is case study with exploratory, descriptive and qualitativequantitative approach. Analyzing the results of the questionnaire, it is considered feasible to implement a flexible benefits program in the company, since $72 \%$ of respondents believed that flexible benefits are important for talent retention and motivation of staff and $69 \%$ are not satisfied with the benefits offered by the company.
\end{abstract}

Keywords: Flexible Benefits. Retention. Talents. Motivation. 


\section{INTRODUÇÃO}

Com a mudança de paradigmas organizacionais, novos modelos de gestão de pessoas estão sendo adotados pelas organizações, com isso, entender o perfil de seus funcionários e oferecer a cada um, o que melhor atenda às suas necessidades, é essencial. São as pessoas que inovam, criam e agregam valor aos serviços e produtos, esta é uma das razões para que estejam motivadas e comprometidas para atender os objetivos da instituição, razão pelo qual devem ter asseguradas a sua qualidade de vida no ambiente laboral (PINTO; KEMMER; FILIPPIM, 2011).

Entretanto, Bernardim e Araújo (2016) corroboram com essa visão citando que, as organizações precisam obter a satisfação dos trabalhadores para atingir seus objetivos. Mas ainda, precisam controlar os custos para preservar a rentabilidade. Para tanto, a gestão de pessoas e as políticas de remuneração passam a desempenhar um importante papel na administração das empresas (BERNARDIM; ARAÚJO, 2016)

Um dos modelos utilizados pelos gestores de recursos humanos é o de benefícios flexíveis, um plano de benefício versátil ao estereótipo de cada um, bem como às suas tarefas diárias. Conforme Decenzo e Robbins (2001) os benefícios apresentados pelos empregadores influenciam no aceite do emprego ofertado aos candidatos e se, após a contratação, os trabalhadores irão permanecer na empresa. Neste contexto, os profissionais de recursos humanos, compreendem a necessidade de melhorias nos processos de remuneração e benefícios oferecidos, tendo em vista que estes são de extrema importância no momento de decidir entre manter-se na empresa ou optar por uma nova oportunidade no mercado de trabalho (DECENZO; ROBBINS, 2001).

O plano de benefícios flexíveis utilizado pelas empresas é definido por Marras (2012) como o escolhido pelos empregados entre o já disponibilizado pela organização e que melhor se enquadram nas suas necessidades do momento e estão ligados diretamente ao cargo exercido. Para Boog e Boog (2002, p. 399) "os benefícios flexíveis consistem na concessão de um conjunto de benefícios que têm como princípio o reconhecimento das necessidades de cada indivíduo considerando o grupo familiar em que ele se insere".

Diante a estes conceitos, foi desenvolvido um estudo em uma indústria de autopeças localizada em Caxias do Sul. Com 24 anos de atividades, a empresa conta com a colaboração de 196 funcionários e é reconhecida como um dos principais fabricantes de sistemas de freios para linha pesada e componentes automotivos para as linhas leve, pesada e agrícola para o mercado brasileiro e América Latina, fornecendo para os segmentos de reposição e fabricação de equipamentos originais.

Para o desenvolvimento da pesquisa determinou-se o seguinte objetivo geral: investigar o que pensam os colaboradores quanto à implantação de um plano flexível de benefícios. Para tanto, determinou-se como objetivos específicos: caracterizar o perfil dos respondentes; identificar os 
benefícios que a empresa oferece; e verificar o nível de satisfação dos funcionários em relação aos benefícios oferecidos pela empresa.

O trabalho está estruturado em introdução, que resume de forma breve o tema abordado e o local de aplicação da pesquisa; fundamentação teórica, abordando os conceitos que deram suporte à pesquisa; procedimentos metodológicos, que aborda o método de pesquisa e as técnicas utilizadas; análise e discussão dos dados; e por último, as considerações finais.

\section{FUNDAMENTAÇÃO TEÓRICA}

A seguir é apresentada a fundamentação teórica que abordará os conceitos que deram suporte à pesquisa.

\subsection{Benefícios}

A remuneração não é vista somente como forma de pagamento de um trabalho desenvolvido pelos colaboradores, mas também como forma de vantagens adicionais para melhorar sua vida. Marras (2011) denomina benefícios como um conjunto de programas ofertados pela empresa que incorporado ao salário caracterizam a remuneração do funcionário, tendo como objetivos atender as necessidades tanto do empregado quanto do empregador. Proporcionando, em alguns casos, a diminuição de indicadores de rotatividade, níveis de estresse e aumentando as condições básicas de trabalho como, por exemplo, a higiene.

Antigamente, esses benefícios eram oferecidos para garantir aos empregados felicidade e saúde, investia-se no tempo de permanência fora da empresa, dando maior ênfase as férias programadas e aos eventos sociais (DECENZO; ROBINS, 2001). Os autores mencionam também que, embora essas vantagens devam ser oferecidas para atrair e manter os bons trabalhadores, elas acabam não afetando diretamente no desempenho dos profissionais, porém a falta delas gera insatisfação, aumentando os índices de absenteísmo e rotatividade.

Cerca de $40 \%$ dos custos com folha de pagamento são representados pelos benefícios, desta forma, os empregadores esperam que os colaboradores sejam produtivos e apoiem a empresa. Porém, atualmente, os benefícios são considerados direitos reivindicados pelos trabalhadores e não mais vantagens oferecidas pelas empresas (BOHLANDER; SNELL, 2009). Desta forma, quando a organização desenvolver um plano de benefícios é necessário levar em conta alguns aspectos, como: os custos e valores, os propósitos, as responsabilidades da gestão e os critérios de avaliação (CHIAVENATO, 2014).

Bohlander e Snell (2009) colocam que além dos aspectos citados por Chiavenato (2014), a empresa deve considerar o plano de benefícios como qualquer outro elemento do departamento 
de recursos humanos, por isso deve basear-se em objetivos específicos, levando em consideração diversos fatores como, por exemplo, tamanho e localização da empresa, lucratividade e padrões da indústria. Acrescentam também, a necessidade de haver compatibilidade desses fatores com o plano de remuneração da empresa, sua filosofia e suas políticas.

\subsubsection{Tipos de benefícios}

Existem muitos tipos de benefícios, isso interfere na definição de uma classificação correta, mas Marras (2011) e Lacombe (2011) propõem alguns tipos de benefícios variáveis de acordo com a legislação, com os parâmetros da empresa ou mesmo com as necessidades dos funcionários. Lacombe (2011) divide os benefícios em três módulos:

a) encargos sociais: são todos os benefícios regulamentados pela lei, assim como, décimoterceiro, férias, repouso semanal remunerado, despesas rescisórias e salário família;

b) benefícios concedidos pela empresa: aqui enquadram-se os benefícios definidos em convenções coletivas, os prestados pela empresa por vontade própria como estratégia competitiva;

c) plano cafeteria ou flexível como é conhecido popularmente: este plano oferece ao funcionário algumas opções de benefícios que podem ser escolhidas conforme suas necessidades.

Os planos de benefícios podem também variar de acordo com o nível hierárquico dos funcionários, sendo eles: estratégico, tático ou operacional. O nível estratégico tem um plano de benefícios mais elaborado e atrativo, podendo ser mais interessante do que seu próprio salário, já os níveis tático e operacional, acabam tendo pacotes mais básicos de benefícios podendo incluir, por exemplo, cesta básica, transporte e plano de saúde (MARRAS, 2011).

\subsubsection{Objetivos dos benefícios}

O plano de benefícios tem por objetivo atender a duas partes: a empresa e os funcionários. A satisfação da parte organizacional se dá através das necessidades básicas, ou seja, a empresa é responsável por garantir a qualidade de vida dos empregados, o que incide diretamente nos indicadores de recursos humanos. Já a satisfação individual acontece quando o empregado consegue garantir, por meio dos benefícios cedidos pela empresa, uma condição mínima de vida (MARRAS, 2011).

Conforme Marras (2011), as pessoas possuem dois tipos de necessidades, as intrínsecas e as extrínsecas. A primeira é a necessidade intrínseca, que nasce dentro de cada pessoa, geralmente atendendo a parte psicológica, assim como os relacionamentos, por exemplo. A segunda é a 
necessidade extrínseca, ou melhor, os elementos físicos que são atendidos em sua grande maioria pelos pacotes de benefícios oferecidos pela empresa, assim como seguros, assistências, alimentação e transporte (MARRAS, 2011).

Para Chiavenato (2014) os benefícios têm como objetivo atender as necessidades particulares dos funcionários satisfazendo diversos aspectos individuais, econômicos e sociais. Desta forma, a empresa deve definir um plano de benefícios adequado para cada pessoa considerando as tarefas realizadas durante o dia, seu status e a sua participação na sociedade (CHIAVENATO, 2014).

Bohlander e Snell (2009) elencam os principais objetivos que compõem a maioria dos planos de benefícios oferecidos pelas empresas: melhorar a satisfação do colaborador, atender as necessidades de saúde e segurança, atrair, motivar e reter os funcionários e manter-se competitivo no mercado de trabalho. É preciso muita atenção no momento de criar um plano de benefícios levando em conta a diversidade de benefícios, o que cada indivíduo prefere, o custo e o valor disponível para ser investido (BOHLANDER; SNELL, 2009).

Wood Jr. e Picarelli Filho (1999) mencionam que o pacote tradicional de benefícios está sendo ameaçado por três motivos: primeiro, devido às mudanças da empresa no que se trata dos níveis hierárquicos, segundo, a diferença dos perfis dos trabalhadores, e por último, a dúvida se o plano é viável ou não levando em conta a satisfação dos colaboradores e o custo que a empresa tem para manter o pacote. Para facilitar a criação, aplicação e administração do pacote de benefícios, é interessante flexibilizar o plano padrão, onde os funcionários podem optar por aquilo que mais lhe agrada, evitando gastos desnecessários por parte da empresa e descontentamento por parte dos colaboradores (BOHLANDER; SNELL, 2009).

\subsubsection{Benefícios Flexíveis}

A criação dos pacotes de benefícios flexíveis ocorreu há cerca de 20 anos com o propósito de dividir os custos com os funcionários, visto que as despesas cresciam aproximadamente $10 \%$ ao ano. Tão logo a inovação foi apresentada, percebeu-se que mais vantagens poderiam ser tiradas desta novidade, uma delas foi valorização dos benefícios por parte dos empregados devido ao fato de poderem escolher o que mais Ihes interessaria (BOOG; BOOG, 2002).

Dessler (2003) compara o plano flexível de benefícios com um plano de cafeteria, pois assim como nos cafés, os funcionários podem escolher através de cardápios qual benefício é melhor para seu estilo de vida. $\mathrm{O}$ autor acrescenta que o colaborador mesmo podendo eleger seu plano ideal, irá se deparar com duas limitações no momento da opção, isto é, o custo e a inclusão de alguns itens obrigatórios como, por exemplo, o seguro desemprego. 
O perfil do trabalhador contemporâneo mudou muito, atualmente cerca de $90 \%$ da mão de obra é composta por pessoas sem filhos, solteiras ou casais onde ambos possuem fonte de renda, essa mudança justifica a implantação de um pacote de benefícios flexíveis já que o plano padrão não satisfaz mais o novo estereótipo presente na sociedade (ROBBINS, 2005). O autor defende a existência de três planos de benefício flexíveis mais utilizados:

a) planos modulares: são criados módulos de benefícios de acordo com grupos de pessoas, podendo ser agregado um ou mais módulos, conforme necessidade específica;

b) planos nucleares: um núcleo é criado padronizando alguns benefícios básicos, um cardápio de benefícios adicionais fica a disposição de cada um para que conforme necessidade sejam adquiridos através de um crédito de benefícios;

c) planos de créditos flexíveis: os funcionários ficam livres para escolher o que acharem mais conveniente, dentro do valor estipulado pelo pacote, sendo este o mais vantajoso uma vez que pode ser usado de diversas formas.

Pontes (2007) defende a existência de duas modalidades de flexibilização, a primeira é definir o custo de cada benefício e um valor limite por funcionário, podendo variar de acordo com o nível hierárquico ocupado na empresa. A segunda alternativa é misturar os benefícios fixos com opcionais, neste modelo a empresa fornece um plano básico juntamente com as opções flexíveis e o funcionário pode escolher em melhorar o plano básico ou um novo benefício.

\subsubsection{Objetivos da implantação dos benefícios flexíveis}

As empresas estão investindo em pacotes menos rígidos onde cada um escolhe o que melhor se adapta às suas necessidades proporcionando uma melhor relação entre empresa e funcionário (WOOD JR.; PICARELLI FILHO, 1999). Os autores comparam esta relação com a de um fornecedor com seus clientes, onde a responsabilidade de escolha passa a ser total do colaborador modificando a visão paternalista que existia antigamente.

Com um plano de benefícios flexíveis a empresa consegue modificar a visão que se tinha em que benefícios eram sinônimos de custos, passando a significar um fator motivacional. Isso ocorre pelo simples fato de reconhecer que cada ser é individual em suas necessidades, desejos e sonhos, sendo permitido que escolham o que acham pertinente para sua satisfação e motivação (ROBBINS, 2005).

Boog e Boog (2002) relacionam quatro motivos para implantação dos benefícios flexíveis na empresa. Em primeiro lugar o autor menciona a transferência da responsabilidade das escolhas para o funcionário e não mais para a empresa. O segundo é a garantia de ter diversas opções para escolher, diferentemente do plano tradicional. O terceiro é a utilização do sistema como forma de 
atrair e reter as pessoas e, por último, a possibilidade de mudar de pacote de acordo com a mudança de suas necessidades.

\subsubsection{Prós e Contras dos Benefícios Flexíveis}

A implantação e administração de um plano flexível de benefícios pode se tornar complexa dependendo do número de funcionários e benefícios a ser disponibilizado e também às influências da legislação. Desta forma, algumas empresas optam pela contratação de outra empresa para cuidar destes planos, pagando pelo serviço prestado (BOHLANDER; SNELL, 2009). Entretanto, algumas pessoas desaprovam o plano flexível pelo fato de precisarem desprender muito tempo para eleger os benefícios e por isso acabam fazendo más escolhas (DESSLER, 2003).

O novo modelo de pacotes de benefícios requer a união entre a empresa e o funcionário, ambos precisam estar preparados para trabalhar desta forma, pois este laço promoverá uma melhoria no relacionamento e na cultura empresarial. Pelo fato de ser um plano mais elaborado, é preciso ter atenção e cuidado nesta prática, Wood Jr. e Picarelli Filho (1999) ressaltam que esta complexidade pode trazer algumas dificuldades, assim como:
a) custo com a implantação do sistema;
b) custo com a manutenção;
c) utilização exagerada de alguns itens;
d) perda de alguns itens.

Lacombe (2011) defende o uso dos benefícios como vantagem para atrair e reter pessoas. Esta regalia pode significar aumento de produção e redução de rotatividade, por exemplo, porém se houver necessidade de retirar os benefícios concedidos, a insatisfação será maior do que a satisfação gerada no momento da concessão. Isso acontece, pois, os funcionários entendem que o benefício se torna um direito adquirido e a falta dele é entendida como uma diminuição da remuneração.

Diante os prós e contras apresentados, o plano flexível de benefícios ainda é considerado benéfico pelo fato de proporcionar satisfação e motivação dos funcionários, a união entre empregado e empregador e melhor controle dos custos, mesmo sem haver redução considerável (BOOG; BOOG, 2002).

\section{PROCEDIMENTOS METODOLÓGICOS}

A pesquisa caracteriza-se quanto aos fins como pesquisa exploratório-descritiva, com uma abordagem qualiquantitativa. Vergara (2000) define pesquisa exploratória como aquela em que há pouco conhecimento acumulado e tem o objetivo de levantar hipóteses sobre assunto pouco 
explorado. Para Figueiredo (2008), a pesquisa descritiva tem como objetivo descrever as características do objeto de estudo através de dados coletados por meio de questionários proporcionando a transcrição exata dos fatos estudados. A pesquisa descritiva pode se aproximar da exploratória, pois além de identificar relações entre os elementos estudados, pode sugerir uma visão diferenciada do problema de pesquisa (GIL, 2007).

Quanto à abordagem classifica-se como qualitativa com algum recurso da pesquisa quantitativa, por meio da utilização de estatística simples. A abordagem qualiquantitativa, permite a relação entre os dados obtidos e a investigação dos sentimentos, ou seja, o esclarecimento dos resultados alcançados quantitativamente através das amostras qualitativas (FIGUEIREDO, 2008).

O método de pesquisa a ser empregado é o estudo de caso que diante as diversas maneiras de pesquisa é o mais utilizado quando não se tem muito conhecimento sobre os fatos e quando o foco está em algum evento do cotidiano (YIN, 2005). A utilização desta técnica é recomendada para encontrar o motivo pelo qual determinado fato ocorreu, possibilitando maior veracidade aos dados coletados e melhor entendimento do fato (GIL, 2007).

Figueiredo (2008, p.104) descreve estudo de caso como sendo "um estudo profundo e exaustivo de um ou poucos objetos, de maneira que permita seu amplo e detalhado conhecimento". O autor ainda acrescenta alguns objetivos para o uso deste método, assim como: exploração de acontecimentos diários, criação de suposições ou teorias para determinado acontecimento, conservação do caráter do objeto de estudo, entre outros.

O estudo teve como população os 196 funcionários ativos da empresa Alfa' Indústria de Auto Peças LTDA. Rudio (1981) caracteriza população como sendo um grupo de pessoas habitantes do mesmo espaço, como por exemplo, a soma de todos os funcionários de determinada empresa, sendo variável de acordo com objetivo e local da aplicação da pesquisa. Marconi e Lakatos (2007, p. 41) definem população como "conjunto de seres animados ou inanimados que apresentam pelo menos uma característica em comum".

A pesquisa foi aplicada para os funcionários do setor de produção, totalizando 185 funcionários. Esta delimitação da população é conceituada como amostra que para Marconi e Lakatos (2007) nada mais é do que uma parte do todo a ser estudado. Rudio (1981) complementa a definição de Marconi e Lakatos (2007) definindo amostra como uma parcela do universo com representatividade fidedigna, proporcionando credibilidade dos resultados obtidos.

A coleta de dados foi realizada de forma qualiquantitativa por meio de questionário impresso com perguntas abertas e fechadas. Esta técnica pode apresentar vantagens e desvantagens por se tratar de uma ferramenta de pesquisa com perguntas em série que são respondidas sem a presença do pesquisador (MARCONI; LAKATOS, 2007). As autoras relacionam

\footnotetext{
${ }^{1}$ Para preservar a confidencialidade da empresa, como foi informado no momento da aplicação da pesquisa, foi utilizada a identificação como empresa Alfa.
} 
algumas vantagens como, por exemplo, economia de tempo, respostas rápidas, alcance de um maior número de respondentes, entre outras. E desvantagens como, baixo índice de retorno dos questionários enviados, perguntas não respondidas, retorno das respostas fora do período designado.

Para efetuar a análise foi utilizada a técnica estatística descritiva, a fim de caracterizar a amostra selecionada. Conforme afirmam Sampieri, Collado e Lúcio (1998), um estudo descritivo é aquele que se preocupa em medir e expor como um fenômeno se manifesta em determinadas situações ou eventos.

\section{ANÁLISE E DISCUSSÃO DOS DADOS}

A aplicação do questionário foi realizada com o objetivo de conhecer o perfil dos respondentes, verificar o nível de satisfação dos funcionários em relação aos benefícios oferecidos pela empresa e o que pensam sobre a implantação de um plano flexível de benefícios. E também, para identificar quais benefícios julgam ser relevantes e quanto estariam dispostos a colaborar caso um plano de benefícios fosse implantando na empresa. A pesquisa foi realizada no mês de agosto de 2015.

Para o desenvolvimento da pesquisa foi realizada uma reunião informativa para os funcionários sobre os fins da pesquisa. Foram distribuídos 185 questionários totalizando 94\% dos colaborados ativos. Desses, foram devolvidos 160 , sendo que 11 foram anulados pelo fato de não estarem devidamente respondidos e 149 foram considerados válidos para realização da pesquisa. A seguir serão apresentados os resultados, análise e interpretação dos resultados obtidos na pesquisa.

O perfil dos entrevistados foi resultante do levantamento dos seguintes dados: idade, gênero, tempo de empresa, estado civil, número de dependentes e escolaridade, elementos que podem influenciar diretamente na escolha dos benefícios. A seguir, serão apresentados os resultados de cada tópico individualmente, seguidos de um único gráfico que demonstra o perfil predominante dos participantes.

A tabela 1 demonstra as faixas de idade, a quantidade e o percentual correspondente das respostas obtidas. Verifica-se que a maioria dos colaboradores tem idade de até 30 anos, representando $53 \%$ do total da pesquisa, este resultado pode ser atribuído ao fato de ter trocado a diretoria, uma vez que a faixa etária do diretor atual é semelhante ao dos funcionários. 
Tabela 1 - Idade dos participantes

\begin{tabular}{ccc}
\hline Idade & No de Respondentes & Porcentagem \% \\
\hline até 25 anos & 36 & $24 \%$ \\
26 até 30 anos & 43 & $29 \%$ \\
31 até 35 anos & 23 & $15 \%$ \\
36 até 40 anos & 14 & $9 \%$ \\
41 até 50 anos & 29 & $19 \%$ \\
mais de 50 anos & 4 & $3 \%$ \\
\hline
\end{tabular}

Fonte: Elaborado pelos autores (2016).

Conforme Tabela 2, verifica-se quantos homens e mulheres trabalham na empresa, indicador relevante para a escolha dos benefícios, tendo em vista que as necessidades femininas se diferem das masculinas. Conforme dados, percebe-se que o gênero feminino representa $54 \%$ dos respondentes. Isso ocorre em virtude das tarefas desempenhadas na empresa que são, na sua maioria, montagem de produtos leves, necessitando de mão de obra masculina apenas nos setores de usinagem, injeção, lavagem e polimento.

Tabela 2 - Gênero dos participantes

\begin{tabular}{ccc}
\hline Gênero & No de Respondentes & Porcentagem \% \\
\hline Feminino & 80 & $54 \%$ \\
Masculino & 69 & $46 \%$ \\
\hline
\end{tabular}

Fonte: Elaborado pelos autores (2016).

Conforme pode ser observado na tabela 3, os indicadores apontam que $63 \%$ dos colaboradores são casados, este perfil demonstra que a empresa é socialmente responsável por mais pessoas e o profissional, por consequência, tem um maior grau de comprometimento com o trabalho. Este fator pode influenciar no momento de optar pelo benefício que melhor atenda suas necessidades. 
Tabela 3 - Estado Civil dos participantes

\begin{tabular}{ccc}
\hline Estado Civil & No de Respondentes & Porcentagem $\%$ \\
\hline Solteiro & 48 & $32 \%$ \\
Casado & 94 & $63 \%$ \\
Separado & 6 & $4 \%$ \\
Divorciado & 0 & $0 \%$ \\
Viúvo & 1 & $1 \%$ \\
\hline
\end{tabular}

Fonte: Elaborado pelos autores (2016).

O número de dependentes é um dado considerável para a pesquisa, tendo em vista que os benefícios têm como objetivo atender as necessidades particulares dos funcionários, conforme é apresentado na tabela 4. Desta forma é preciso considerar quantas pessoas estão envolvidas, direta ou indiretamente na seleção dos benefícios. Com a tabulação dos dados, percebe-se que $38 \%$ dos colaboradores não têm dependentes e 31\% tem apenas um dependente. Esse cenário é predominante nos dias atuais, pois diferente do que ocorria no passado as famílias estão diminuindo e as prioridades já não são mais as mesmas.

Tabela 4 - Número de dependentes

\begin{tabular}{ccc}
\hline No de dependentes & No de Respondentes & Porcentagem \% \\
\hline Nenhum & 57 & $38 \%$ \\
1 & 46 & $31 \%$ \\
2 & 19 & $13 \%$ \\
3 & 14 & $9 \%$ \\
4 & 9 & $6 \%$ \\
5 & 0 & $0 \%$ \\
Mais de 5 & 4 & $3 \%$ \\
\hline
\end{tabular}

Fonte: Elaborado pelos autores (2016).

Também foi atribuída à pesquisa a questão sobre quanto tempo o respondente está na empresa. Este fator poderá interferir nas respostas, uma vez que o tempo de empresa influencia na satisfação, motivação e desempenho do funcionário. A empresa está passando por um momento de reestruturação o que impacta não só na faixa etária, conforme demonstrado na tabela 1, como também no tempo de empresa, isso explica o porquê $52 \%$ dos colaboradores terem entre 1 e 5 anos de empresa e apenas 1\% está há mais de 10 anos na empresa, conforme dados apresentados na tabela 5. 
Tabela 5 - Tempo de empresa

\begin{tabular}{ccc}
\hline Tempo de empresa & No de Respondentes & Porcentagem $\%$ \\
\hline Menos de 1 ano & 40 & $27 \%$ \\
De 1 a 5 ano & 78 & $52 \%$ \\
De 5 a 10 anos & 29 & $19 \%$ \\
10 a 20 anos & 2 & $1 \%$ \\
\hline
\end{tabular}

Fonte: Elaborado pelos autores (2016).

O grau de instrução foi incorporado ao questionário, pois assim como os itens anteriores, faz relação direta com a escolha dos benefícios e com as respostas das demais questões da pesquisa. Através da tabela 6, percebe-se que o nível de escolaridade não é tão elevado, apenas $11 \%$ estão na faixa de ensino superior, $41 \%$ possuem ensino fundamental e $48 \%$ cursaram o ensino médio, entretanto esses valores são justificáveis pelo perfil de cargo que não exige além do ensino médio.

Tabela 6 - Escolaridade dos participantes

\begin{tabular}{ccc}
\hline Escolaridade & No de Respondentes & Porcentagem \% \\
\hline Ensino Fundamental Incompleto & 31 & $21 \%$ \\
Ensino Fundamental Completo & 30 & $20 \%$ \\
Ensino Médio Incompleto & 24 & $16 \%$ \\
Ensino Médio Completo & 48 & $32 \%$ \\
Ensino Superior Incompleto & 6 & $4 \%$ \\
Ensino Superior Completo & 10 & $7 \%$ \\
\hline
\end{tabular}

Fonte: Elaborado pelos autores (2016).

O perfil predominante foi elaborado para que haja melhor compreensão da pesquisa e análise das características da grande parte dos participantes. O resultado está ilustrado por meio de gráfico contendo apenas o maior percentual de idade, estado civil, tempo de empresa, escolaridade, gênero e número de dependentes. 
Gráfico 1 - Perfil predominante

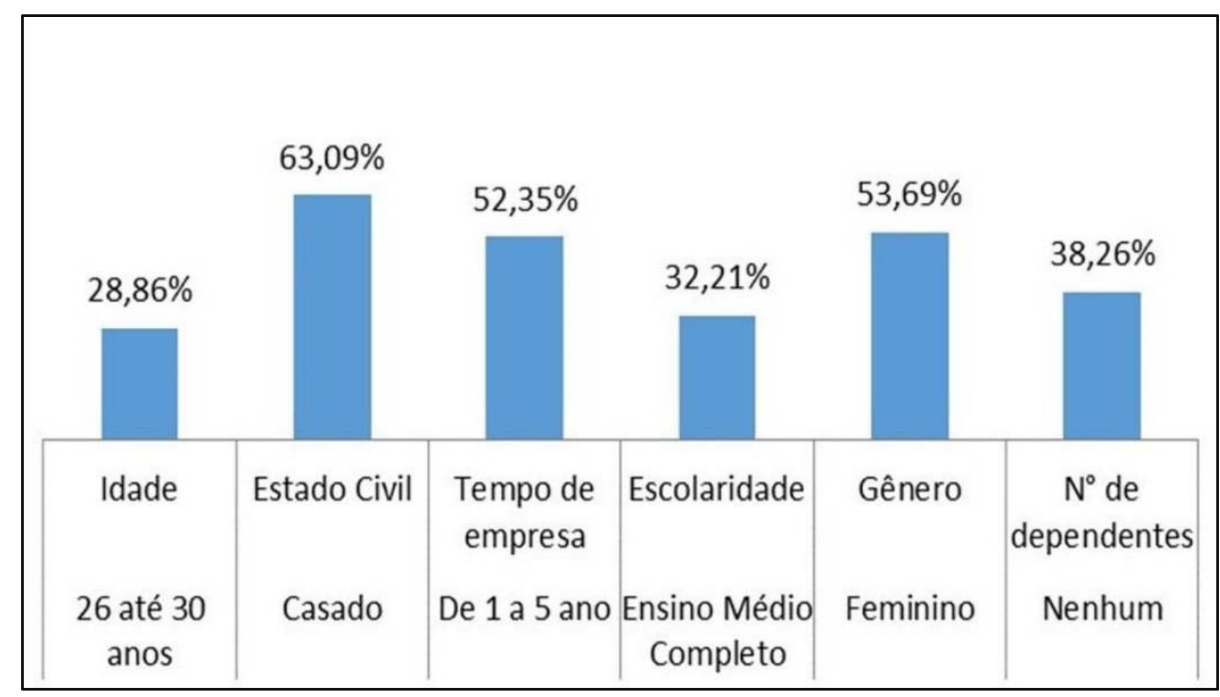

Fonte: Elaborado pelos autores (2016).

Os números demonstrados no gráfico 1 traduzem o perfil predominante dos funcionários da empresa em que $28,86 \%$ tem idade entre 26 e 30 anos, 63,09\% são casados, 52,35\% atuam na empresa em um período de 1 a 5 anos, 32,21\% concluíram o ensino médio, 53,69\% são do gênero feminino e $38,26 \%$ não têm filhos.

O questionário aplicado foi elaborado não só com o intuito de conhecer o perfil dos respondentes como também para identificar o nível de satisfação, o grau de conhecimento, interesse e importância que os funcionários atribuem aos benefícios disponibilizados pela organização. Para coletar essas informações, foram elaboradas nove perguntas fechadas sendo que sete delas deveriam ser respondidas de acordo com uma escala de 1 a 5 , sendo 5 concordo totalmente e 1 discordo totalmente. As outras duas questões serviram para identificar a importância e o conhecimento dos entrevistados em relação ao tema. As respostas serão apresentadas em forma de gráfico com os resultados em percentual, facilitando a análise e interpretação da pesquisa.

O primeiro questionamento foi realizado para saber se os funcionários têm conhecimento da quantidade de benefícios oferecidos pela empresa. A maior parte dos respondentes, 32\%, acredita que sejam oferecidos apenas dois benefícios quando na verdade a empresa oferece acima de quatro, sendo eles: plano de saúde, vale transporte, alimentação, auxílio creche, convênio com academia, convênio com clínica odontológica e convênio com posto de combustível. Apenas 5\% responderam que a empresa oferece mais de quatro benefícios, este baixo índice pode demonstrar que existe uma grande deficiência na comunicação e na divulgação por parte da empresa. Este assunto merece atenção, tendo em vista que os benefícios podem ser utilizados como forma estratégica de retenção de talentos. 
Gráfico 2 - Quantos benefícios a empresa oferece hoje

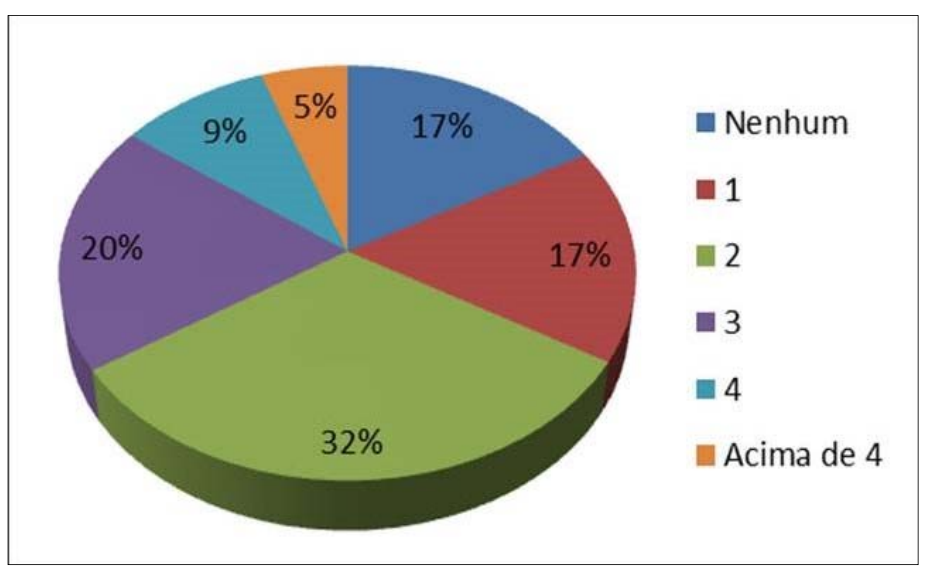

Fonte: Elaborado pelos autores (2016).

A segunda pergunta foi aplicada com a intenção de saber se os benefícios influenciam ou não no momento de optar em permanecer na empresa ou aceitar uma nova proposta de emprego. De acordo com o gráfico 3, 72\% aceitariam outra proposta de emprego levando em consideração o poder de escolha de seus benefícios, índice que merece atenção tendo em vista que grande parte dos colaboradores desconhece os benefícios disponibilizados pela empresa.

Gráfico 3 - Você trocaria de emprego se tivesse a oportunidade de escolher seus benefícios?

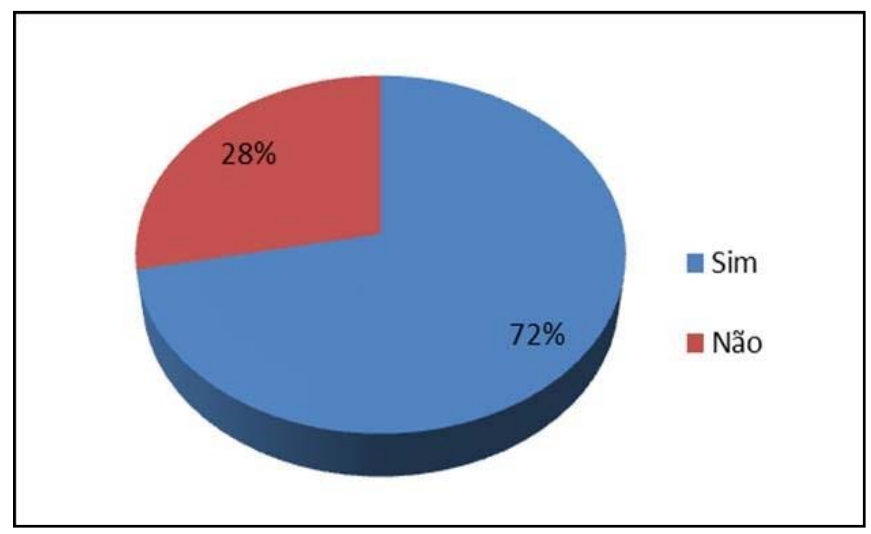

Fonte: Elaborado pelos autores (2016).

As perguntas apresentadas a seguir foram respondidas levando em consideração a escala de 1 a 5 , sendo 1 discordo totalmente e 5 concordo totalmente. A "pergunta estou satisfeito com os benefícios oferecidos pela empresa" apresenta um alto índice de insatisfação, os itens discordo totalmente e discordo parcialmente somam $69 \%$ das respostas coletadas. Este indicador pode ter ficado negativo devido à falta de conhecimento dos funcionários em relação aos benefícios oferecidos pela empresa e por consequência influenciar as respostas das demais questões. 
Gráfico 4 - Estou satisfeito com os benefícios oferecidos pela empresa

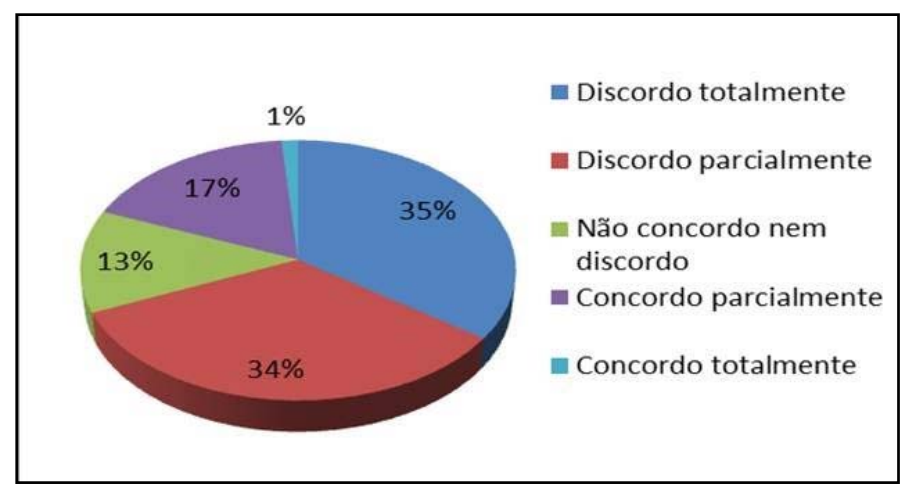

Fonte: Elaborado pelos autores (2016).

Quando interrogados se os benefícios satisfazem as necessidades básicas, 28\% responderam que discordam totalmente, $22 \%$ discordam parcialmente, $21 \%$ não concordam nem descordam, $24 \%$ concordam parcialmente e apenas $5 \%$ concordam totalmente. Pelos números apresentados compreende-se que os benefícios oferecidos pela empresa não satisfazem por completo as necessidades dos colaboradores, esta constatação pode dar-se pelo fato de não poderem escolher seus benefícios e terem que utilizar o que é disponibilizado, sendo útil ou não.

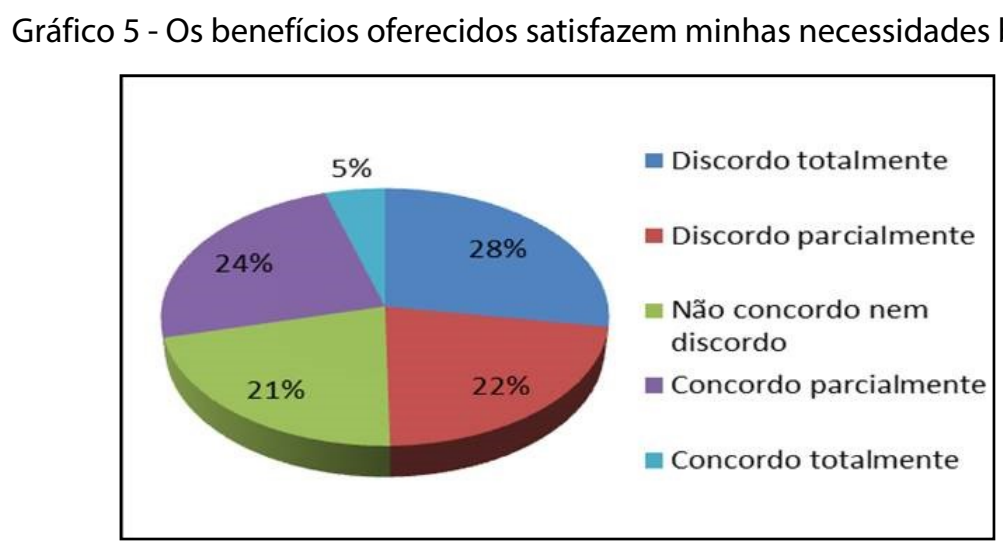

Fonte: Elaborado pelos autores (2016).

A questão "os benefícios facilitam a minha vida fora do trabalho" apresentou um índice um pouco mais elevado do que as perguntas anteriores. O nível de satisfação atingiu $34 \%$ entre concordo totalmente e concordo parcialmente, isso quer dizer que apesar de não estarem contentes e os benefícios não atenderem totalmente suas necessidades básicas, ainda assim é possível que se tenha vantagem, porque de uma forma ou de outra a utilização dos meios acaba facilitando a vida fora do ambiente de trabalho. 
Gráfico 6 - Os benefícios facilitam a minha vida fora do trabalho

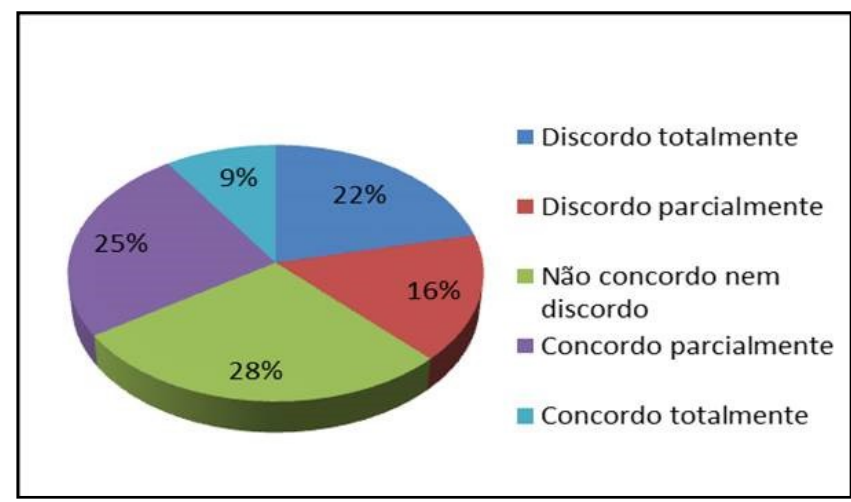

Fonte: Elaborado pelos autores (2016).

Na pergunta "considero os benefícios oferecidos como um incentivo ao trabalho", 17\% acreditam de fato que o incentivo ao trabalho depende dos benefícios que a empresa concede a cada um, porém $28 \%$ discordam totalmente da afirmativa. Analisando os números acima, percebese que indiferente do benefício oferecido hoje pela empresa, os funcionários não se sentem mais ou menos motivados a trabalhar, de acordo com o gráfico 2 os colaboradores não possuem conhecimento de todos os benefícios que a empresa oferece, este pode ser um dos fatores responsáveis por este resultado.

Gráfico 7 - Considero os benefícios oferecidos como um incentivo para o trabalho

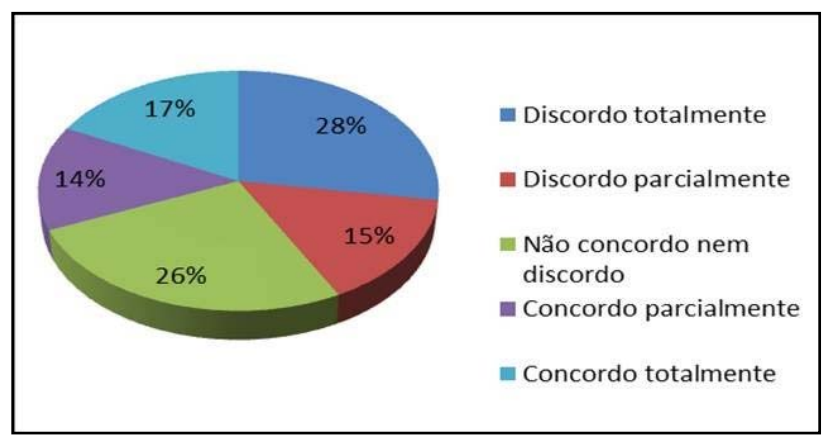

Fonte: Elaborado pelos autores (2016).

Na pergunta "se estiver dentro das minhas reais necessidades, não me importo em participar com um percentual para adquirir um benefício" é possível verificar o interesse dos respondentes para com os benefícios, conforme gráfico $8,26 \%$ concordam totalmente enquanto $13 \%$ discordam totalmente. Através destes dados, conclui-se que os benefícios são valorizados pelos respondentes que se disponibilizam a cooperar com um percentual para adquirir determinado benefício, este fator poderá facilitar no momento de aprovação da ferramenta. 
Gráfico 8 - Se estiver dentro das minhas reais necessidades, não me importo em participar com um percentual para adquirir um benefício

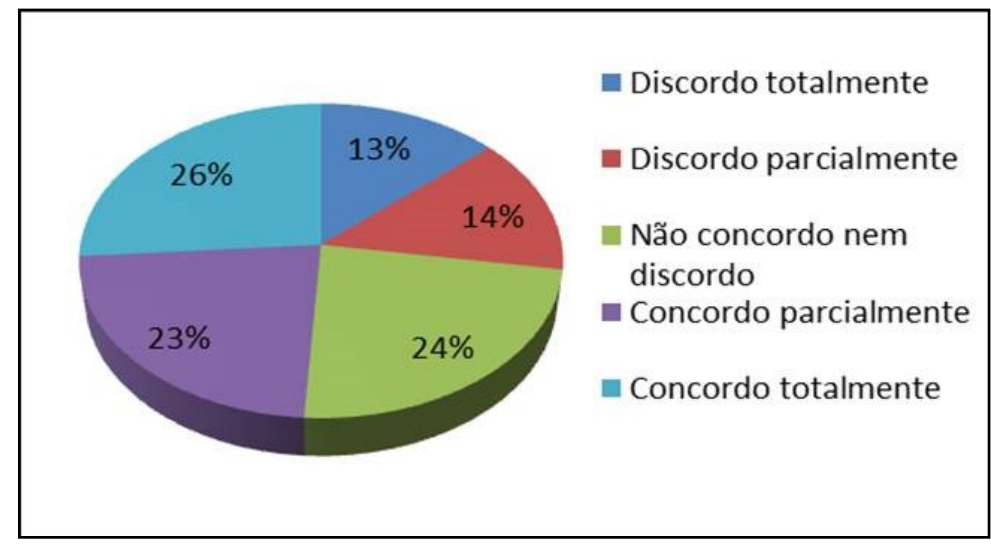

Fonte: Elaborado pelos autores (2016).

É possível verificar que a maioria dos participantes defende a importância de implantar um plano flexível de benefícios, $42 \%$ concordam totalmente com esta prática, enquanto apenas $1 \%$ discorda totalmente e 5\% discordam parcialmente. De encontro com Robbins (2005), o perfil do trabalhador mudou muito e hoje aproximadamente $90 \%$ da mão de obra é composta por pessoas sem filhos, solteiras ou casais onde ambos possuem fonte de renda, essa mudança justifica a implantação de um pacote de benefícios flexíveis já que o plano padrão não satisfaz o novo estereótipo presente na sociedade.

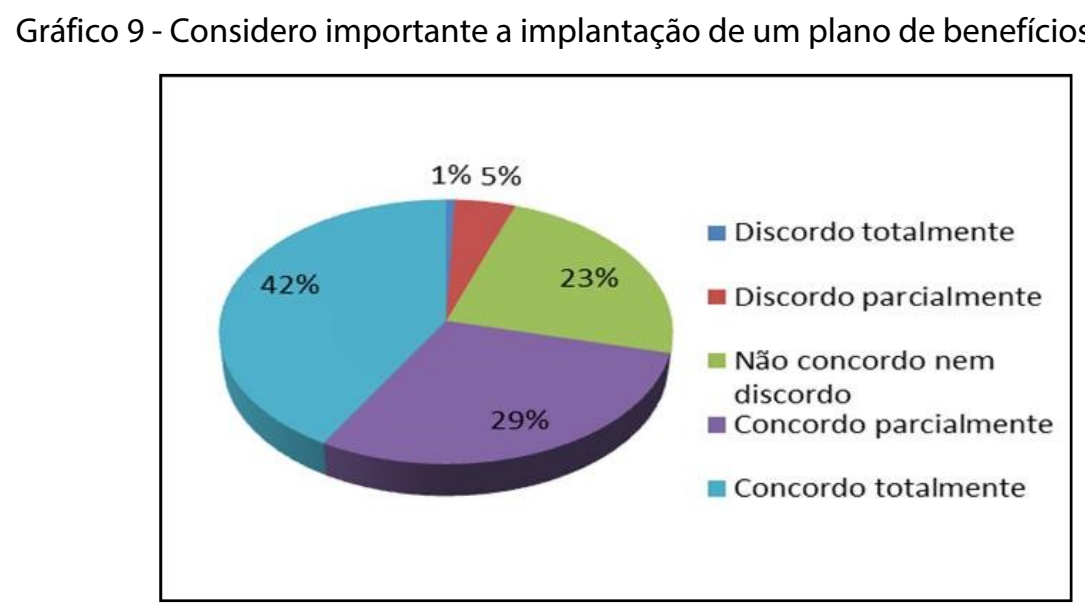

Fonte: Elaborado pelos autores (2016).

Assim como na questão anterior, grande parte dos participantes considera importante para a motivação e retenção de pessoal a utilização de um plano flexível de benefícios. $O$ indicador é de $72 \%$ entre concordo totalmente e concordo parcialmente contra $4 \%$ que discordam seja total ou parcialmente e $24 \%$ não concordam nem discordam. Lacombe (2011) apresenta o uso dos benefícios flexíveis como vantagem para atrair e reter pessoas, conceito que vem de encontro ao resultado obtido com a pesquisa. 
Gráfico 10 - Considero que o plano de benefícios flexíveis é importante para a motivação e retenção de pessoal

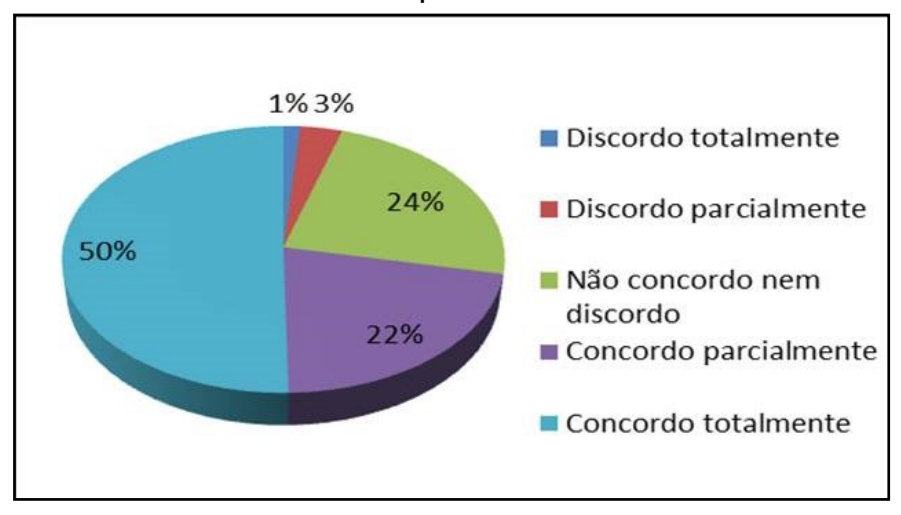

Fonte: Elaborado pelos autores (2016).

Neste momento da pesquisa, foram questionados sobre quais benefícios julgam mais importantes e qual percentual estariam dispostos a contribuir para adquiri-los. Foram sugeridos vinte benefícios para escolha e disponibilizado uma tabela para colocarem sugestões de possíveis benefícios que não estivessem relacionados, devendo preencher com grau de importância e percentual de participação.

Como referência utilizou-se uma escala de 1 a 5 em que 1 significa menor grau de importância e 5 o maior, enquanto o percentual de participação poderia ser escolhido de 1 a 100 conforme julgassem coerente. Abaixo serão apresentados os resultados em ordem crescente, levando em consideração o grau de importância 5 e o percentual que estão dispostos a colaborar apresentado através da média das respostas obtidas. 
Tabela 7 - Classificação dos benefícios e percentual de participação

\begin{tabular}{lccccccc}
\hline \multirow{1}{*}{\multicolumn{1}{c}{ BENEFÍCIOS }} & \multicolumn{5}{c}{ GRAU DE IMPORTÂNCIA } & PERCENTUAL \\
\cline { 2 - 5 } Plano de Saúde & 1 & 2 & 3 & 4 & 5 & DE \\
PuxTICIPAÇÃO \\
Auxilio Cursos & 0 & 1 & 3 & 17 & 128 & $20 \%$ \\
Vale Transporte & 3 & 2 & 7 & 24 & 113 & $23 \%$ \\
Cesta Básica & 6 & 2 & 11 & 20 & 110 & $24 \%$ \\
Vale Refeição & 6 & 4 & 16 & 16 & 107 & $7 \%$ \\
Vale Alimentação & 17 & 4 & 13 & 10 & 105 & $14 \%$ \\
Convênio Odontológico & 10 & 8 & 16 & 24 & 91 & $11 \%$ \\
Auxilio Combustível & 7 & 6 & 15 & 30 & 91 & $11 \%$ \\
Seguro de Vida & 4 & 11 & 22 & 23 & 89 & $20 \%$ \\
Convênio Farmácia & 10 & 4 & 25 & 23 & 87 & $10 \%$ \\
Auxilio Creche & 6 & 1 & 23 & 16 & 83 & $16 \%$ \\
Vale- gás & 33 & 10 & 18 & 33 & 82 & $24 \%$ \\
Assistência Psicológica & 30 & 10 & 29 & 22 & 58 & $18 \%$ \\
Convênio com Ótica & 39 & 16 & 30 & 21 & 46 & $11 \%$ \\
Convênio com Livraria & 47 & 21 & 17 & 30 & 34 & $15 \%$ \\
Assistência Jurídica & 59 & 7 & 34 & 15 & 34 & $9 \%$ \\
Convênio com Academia & 55 & 27 & 33 & 17 & 17 & $11 \%$ \\
Convênio com Clubes & 80 & 26 & 24 & 7 & 12 & $9 \%$ \\
Convênio com Cinema & 70 & 31 & 32 & 7 & 9 & $9 \%$ \\
\hline
\end{tabular}

Fonte: Elaborado pelos autores (2016).

Apenas 19 respondentes julgaram necessário incluir outros benefícios além dos propostos na pesquisa, o número não teve influência no desenvolvimento da proposta por representar 12,75\% dos participantes. Os benefícios citados foram: participação de lucros, transporte próprio da empresa, bonificação, empréstimo com desconto em folha, adiantamento do décimo terceiro salário e serviço de fisioterapia.

\section{CONSIDERAÇÕES FINAIS}

Com a competitividade do mercado é necessário fazer mais para manter os colaboradores comprometidos e transformar a empresa em um ambiente atraente no mercado de trabalho. A implantação de um plano de benefícios flexíveis pode ser uma solução para manter os funcionários leais e conservar a imagem positiva da organização, podendo assim, aumentar a motivação e diminuir os índices de absenteísmo nas empresas. A realização deste estudo possibilitou maior conhecimento sobre o tema, permitindo atender o objetivo geral que foi investigar o que pensam os colaboradores quanto a implantação de um plano flexível de benefícios. 
Os objetivos específicos foram definidos com o intuito de tornar a pesquisa viável, sendo todos efetivamente atendidos. A partir deles conseguiu-se caracterizar o perfil dos funcionários, assim facilitando o entendimento de suas preferências, que como ressaltou Robbins (2005), cada colaborador é individual em suas necessidades, desejos e sonhos. Como também, identificou-se a situação da empresa e a opinião dos funcionários quanto ao que ela oferece.

A fundamentação teórica corroborou na busca pelo entendimento dos assuntos considerados importantes, como também para a análise dos resultados. Sendo que, com a análise dos dados coletados, percebeu-se que $71 \%$ dos respondentes considera importante a implantação de um plano de benefícios flexíveis e $49 \%$ estariam dispostos a contribuir com um percentual para adquirir um benefício. Estes dados contribuem para viabilizar uma futura proposta de um plano de benefícios flexíveis, bem como elencar os benefícios incorporados ao pacote, entre eles, os benefícios já oferecidos hoje pela empresa, sendo plano de saúde, alimentação e transporte.

Ao analisar os dados coletados da pesquisa realizada, constatou-se que há carência na comunicação interna. Desta forma, como sugestão para futuros trabalhos aconselha-se o estudo de implantação de um sistema de endomarketing que assim como o programa de benefícios flexíveis, pode ser utilizado de forma estratégica para reter talentos, motivar os colaboradores e tornar a empresa atraente para atrair novos talentos. 


\section{REFERÊNCIAS}

BERNARDIM, Márcio Luiz; ARAÚJO, Joceliane Antunes. Os benefícios extrassalariais no âmbito da remuneração: um diagnóstico da prática empresarial em um município do interior do estado do Paraná. Navus, Florianópolis, v. 6, n. 2, p. 79-92, abr./jun. 2016.

BOOG, Gustavo; BOOG, Magdalena (Coord.). Manual de gestão de pessoas e equipes: operações. São Paulo: Gente, 2002. v. 2.

BOHLANDER, George; SNELL, Scott. Administração de recursos humanos. 14. ed. São Paulo: Cengage Learning, 2009.

CHIAVENATO, Idalberto. Gestão de pessoas: o novo papel dos recursos humanos nas organizações. 4. ed. Barueri, SP: Manole, 2014.

DESSLER, Gary. Administração de recursos humanos. 2. ed. São Paulo: Prentice Hall, 2003.

DECENZO, David A.; ROBBINS, Stephen P. Administração de recursos humanos. 6. ed. Rio de Janeiro: LTC, 2001.

FIGUEIREDO, Nébia Maria Almeida de. Métodos e Metodologia na Pesquisa Cientifica. 3. ed. São Caetano do Sul, SP: Yendis Editora, 2008.

GIL, Antonio Carlos. Como Elaborar Projetos de Pesquisa. 4. ed. São Paulo: Atlas, 2007.

LACOMBE, Francisco José Masset. Recursos Humanos: princípios e tendências. 2. ed. São Paulo: Saraiva, 2011.

MARCONI, Marina de Andrade; LAKATOS, Eva Maria. Técnicas de pesquisa: planejamento e execução de pesquisas, amostragens e técnicas de pesquisas, elaboração, análise e interpretação de dados. 6. ed. São Paulo: Atlas, 2007.

MARRAS, Jean Pierre. Administração de recursos humanos: do operacional ao estratégico. 14. ed. São Paulo: Saraiva, 2011.

Administração de remuneração. 2. ed. São Paulo: Pearson Education do Brasil, 2012.

MAXIMIANO, Antonio Cesar Amaru. Teoria Geral da Administração: da revolução urbana à revolução digital. 7. ed. São Paulo: Atlas, 2012.

PINTO, Marli Dias Souza; KEMMER, Adélio Alvicio; FILIPPIM, Eliane Salete. Qualidade de Vida no Trabalho na Perspectiva dos Empregados de uma Instituição Financeira. Revista Pensamento Contemporâneo em Administração, Rio de Janeiro, v. 5, n. 3, p. 83-96, set./dez. 2011

PONTES, Benedito Rodrigues. Administração de cargos e salários: carreira e remuneração. 12. ed. São Paulo: LTR, 2007.

ROBBINS, Stephen P. Comportamento Organizacional. 11. ed. São Paulo: Pearson Prentice Hall, 2005.

RUDIO, Franz Victor. Introdução ao projeto de pesquisa científica. 5. ed. Petrópolis, RJ: Vozes, 1981. 
SAMPIERI, Roberto Hernández; COLLADO, Carlos Fernández; LUCIO, María Del Pilar Baptista. Metodología de la investigación. México: McGraw-Hill, 1998.

VERGARA, Sylvia Constant. Projetos e relatórios de pesquisa em administração. 3. ed. São Paulo: Atlas, 2000.

YIN, Robert K. Estudo de Caso: Planejamento e Métodos. Trad. Daniel Grassi. 3. ed. Porto Alegre: Bookman, 2005.

WOOD Jr., Thomaz; PICARELLI FILHO, Vicente. Remuneração Estratégica: a nova vantagem competitiva. 2. ed. São Paulo: Atlas, 1999. 